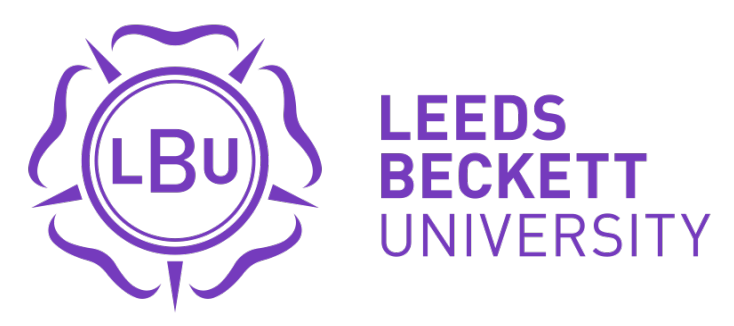

Citation:

Shaw, RA (2017) Professionalising teaching in HE: the impact of an institutional fellowship scheme in the UK. Higher Education Research and Development, 37 (1). pp. 145-157. ISSN 1469-8366 DOI: https://doi.org/10.1080/07294360.2017.1336750

Link to Leeds Beckett Repository record:

https://eprints.leedsbeckett.ac.uk/id/eprint/3778/

Document Version:

Article (Accepted Version)

This is an Accepted Manuscript of an article published by Taylor \& Francis in Higher Education Research and Development on 11 June 2017, available online: http://www.tandfonline.com/10.1080/07294360.2017.1336750

The aim of the Leeds Beckett Repository is to provide open access to our research, as required by funder policies and permitted by publishers and copyright law.

The Leeds Beckett repository holds a wide range of publications, each of which has been checked for copyright and the relevant embargo period has been applied by the Research Services team.

We operate on a standard take-down policy. If you are the author or publisher of an output and you would like it removed from the repository, please contact us and we will investigate on a case-by-case basis.

Each thesis in the repository has been cleared where necessary by the author for third party copyright. If you would like a thesis to be removed from the repository or believe there is an issue with copyright, please contact us on openaccess@leedsbeckett.ac.uk and we will investigate on a case-by-case basis. 


\title{
Professionalising teaching in HE: the impact of an institutional fellowship scheme in the UK
}

\author{
Rob Shaw
}

Faculty of Health and Social Sciences, Leeds Beckett University, City Campus, Leeds, United Kingdom, LS1 $3 H E$

+44 113 8127703; r.a.shaw@leedsbeckett.ac.uk

Rob Shaw is a Learning Technologist in the Faculty of Health and Social Sciences at Leeds Beckett University, UK. He is also undertaking a PhD in Higher Education Research, Evaluation and Enhancement in the Department of Educational Research at Lancaster University, UK.

Word count: 7000 


\title{
Professionalising teaching in HE: the impact of an institutional fellowship scheme in the UK
}

\author{
The professionalisation of teaching in Higher Education has been increasingly \\ prioritised across the globe in response to changes in the scale and nature of \\ Higher Education brought about by massification, marketisation and \\ managerialism. The UK experience has been characterised by the application of \\ codified professional standards and this is of wider interest as perhaps the most \\ developed attempt to formalise and systematise approaches to teacher \\ development utilising such standards. Increasingly, this has focused on the \\ ongoing development of existing staff in addition to new entrants to the \\ profession. Institutional schemes underpinned by the United Kingdom \\ Professional Standards Framework (UKPSF) have rapidly spread throughout the \\ sector offering a route for experienced staff to achieve Fellowships of the UK \\ Higher Education Academy (HEA). However, research into the effects of such \\ schemes on individual participants and institutions has been limited. This article \\ analyses the impact of such a scheme within the Faculty of Health and Social \\ Sciences at Leeds Beckett University in the UK, drawing on data derived from \\ in-depth interviews with scheme participants. Practice theories were applied as a \\ frame for analysis of the developmental impact of the scheme through \\ exploration of the practices involved in participation and how these meshed with \\ other practices related to teaching and learning. This suggested that while such \\ schemes may be an acceptable form of retrospective benchmarking, the ongoing \\ developmental impact may be limited.
}

Keywords: Academic development; continuing professional development; Higher Education Academy Fellowships; practice theories; professional standards; professionalisation; teaching accreditation; teaching enhancement

\section{Introduction}

The professionalisation of teaching in Higher Education (HE) has become an increasingly pressing issue across the globe as the sector adjusts to changes in the scale and nature of $\mathrm{HE}$ within an increasingly global competitive landscape (Land \& Gordon, 2015). Calls are currently being made to unify and formalise approaches to the 
development of HE teachers across Europe (Thornton, 2014, p. 226), approaches to professional competencies are being explored and developed in Australia, Germany and Ireland (Land \& Gordon, 2015, p. 10) and debates abound concerning the development and use of criteria for effective teaching in HE (Devlin \& Samarawickrema, 2010). Against this backdrop, the UK experience provides a useful example of wider interest as perhaps the most developed attempt to formalise and systematise approaches to teacher development utilising codified professional standards.

This study focuses on the relatively recent but rapidly growing phenomenon of institutional schemes underpinned by the United Kingdom Professional Standards Framework (UKPSF) providing access for experienced staff to Fellowships of the UK Higher Education Academy (HEA). The case is explored of the 'Continuing Professional Development route to HEA fellowships' scheme at Leeds Beckett University which is similar in structure to many of the HEA accredited schemes across the sector (Peat, 2015; Spowart, Turner, Shenton, \& Kneale, 2015; Thornton, 2014; van der Sluis, Burden, \& Huet, 2016). It is not a 'course' of study with structured tasks and assessment activities and it does not follow a 'front-ended' model for development typical of postgraduate provision in Teaching and Learning or Academic Practice in HE targeted at the level of new entrants to the profession (van der Sluis et al., 2016). Rather, it provides experienced staff with a supported alternative route to making a direct application for fellowship based on existing experience. This is done through the development and presentation of evidence to make a claim for fellowship which is judged against the UKPSF descriptors by a panel of reviewers from within the University.

HEA-accredited institutional schemes have gained traction relatively rapidly through a broad range of universities within the UK, and the HEA announced the 100th 
scheme to be accredited in May 2015 (Higher Education Academy, 2015). Despite this, research into their effects on individual participants and institutions has been limited. This article explores the experiences of a group of staff who undertook the Leeds Beckett University scheme between 2014 and 2016. Nineteen staff members from one of the University's faculties took part in semi-structured interviews focusing on motivations, engagement patterns and outcomes. Practice theories influenced the focus of the interviews and provided the broad theoretical framework for analysis of the developmental impact. This focused on the nature of the practices involved in participation and the extent of their interaction with the broader 'nexus' of practices related to teaching and learning (Saunders, Sin, \& Dempster, 2015).

\section{Professionalisation of experienced teaching staff through accreditation: The UK experience}

A key focal point for the development of teacher professionalism in HE in the UK has been the United Kingdom Professional Standards Framework (UKPSF). This sets out 'a general description of the activities, knowledge and values central to learning and teaching support roles' (Turner, Oliver, McKenna, Smith, Deepwell, \& Shrives, 2013, p. 9) in order to provide a means to 'benchmark, develop, recognise and reward' teaching and learning roles in HE by providing an 'external indication that a standard has been met' (Turner et al., 2013, p. 6). Unveiled in 2006, the UKPSF was initially adopted across the sector as underpinning for the postgraduate provision in teaching and learning in HE which had largely become a standardised requirement for new staff with teaching roles. Whilst initial efforts were therefore targeted towards teacher professionalism for new entrants to the profession, attention also shifted towards the Continuing Professional Development (CPD) of experienced teaching staff and this intensified with the unveiling of a revised UKPSF in 2011. This placed further 
emphasis on existing staff by introducing four sets of descriptors (Ds) for different levels of fellowship aligned to the different roles that a practitioner might have from associate fellowship of the HEA (D1) through fellowship (D2), to senior fellowship (D3) and beyond to principal fellowship (D4), thus outlining an incremental progression and aiming to provide a potential vehicle for development (Hibbert \& Semler, 2015). These descriptors are underpinned by a set of 'dimensions' defining the areas of activity, knowledge and values involved in successful teaching and learning activity as inter-related components of practice. The rapid development of institutional accreditation schemes has led to strong growth in the proportions of staff holding fellowships across the sector (Hibbert \& Semler, 2015). However, the relative recency of these developments means that further research is needed into their impact within the institutions in which they are provided.

A potentially limiting factor to the developmental impact of accredited schemes emerges from the fact that in many cases universities have introduced policies and targets to encourage participation to effectively make this mandatory for staff without fellowships or equivalent qualifications (van de Sluis et al., 2016). Land's (2001) model of development practices provides a useful framework for analysis of such schemes as forms of academic staff development. This conceptualises the 'orientation' of academic development activity on a continuum between 'domesticating' tendencies serving institutional policy and 'liberating' tendencies aiming to critique and offer alternatives to the status quo. Where participation is underpinned by institutional targets, such schemes are likely immediately to be drawn towards the 'domesticating' end of the continuum and to involve managerial hierarchical orientations. They are likely to require a particular form of organisation and structure to ensure that performance can be monitored and managed. 
Much has been written about the difficulties involved in changing academic practice and the lack of any straightforward relationship between policy and practice, as well as of the many strategies that may be employed in resistance to managerialist initiatives that do not chime with the attitudes, values and practices of academic staff (Trowler, 2008a; Teelken, 2012). These factors may mean that institutional pressures to take part enacted through target setting may limit the potential for schemes to positively impact on learning and teaching. Even where participation is increased, this may involve 'box-ticking approaches' characterised by shallow rather than deep learning processes (Skelton, 2012, pp. 266-7). Peat (2015) is clear on the dangers that such schemes can rapidly become 'tokenistic exercises' in a context in which institutional imperatives to take part have led in many cases to a 'sector-wide race to get as many colleagues as possible recognised within the new competitive marketplace that is HE' (p. 93). It is clear therefore that participation may not automatically lead to positive development and, as Peat (2015, p. 94) notes, the extent to which institutional accreditation schemes can avoid the challenges of box-ticking approaches is likely to depend on the way in which they are operationalised and regarded locally.

Spowart and colleagues (2015) explored the interface between the institutional and the individual factors at work within the scheme at the University of Plymouth through analysis of the experiences of participation of a group of experienced staff. This was undertaken through the theoretical lens of activity theory which aimed to reveal commonalities and contradictions between 'activity systems' at the level of individuals going through the scheme and the organisation aiming to increase the proportion of qualified teaching staff. Their analysis showed that institutional recognition and management championing were important in encouraging participation. However, differences in the activity systems of individuals taking part and of managers 
encouraging participation led to tensions compounded by a mismatch between the activities undertaken during the process of gaining accreditation and the everyday practices of participants. These seemed to result in limitations in how valued the process was perceived to be for some, compounded by a sense of ambiguity towards the HEA and the UKPSF, particularly amongst staff working in disciplines aligned to professional bodies (Spowart et al., 2015, pp. 6-7). These insights are consistent with Crawford's (2010) research which indicated that the HEA has limited influence on academics' development, with the UKPSF being viewed more as a driver for institutional strategy and policy than a force for development (p. 193).

Though Spowart and colleagues' (2015) study took place in a context in which there had been no institutional target for accreditation and in which the motivation for engagement for the majority was described as voluntary, there was a strong sense that taking part was an unavoidable process leading the authors to question whether those taking part were 'truly' volunteers. van der Sluis and colleagues' (2016) research into the outcomes of an institutional scheme at Kingston University took place in a context in which the institutional pressures to participate were much more explicit and in which university targets resulted in direct pressure on staff to take part exerted through appraisal processes and mandatory requirements to achieve Fellowships for promotion and progression. A survey of staff participating in the scheme suggested that there were positive perceptions of the impact of taking part as a form of CPD in terms of stimulating scholarly activities, refreshing understanding of pedagogic practices and raising awareness of the wider HE landscape and the importance of CPD. Thus, staff seemed to have undergone a process of 'making the best out of the situation' for their own practice as a response to institutional pressures (van der Sluis et al., 2016, p. 8). However, the authors are clear that the 'retrospective benchmarking' nature of the 
scheme may serve to limit the developmental impact in that formal engagement ends upon obtaining a fellowship and participants frequently avoid reference to less successful aspects of their practice which may provide rich ground for deeper reflective learning (van der Sluis et al., 2016, p. 6). The type and depth of engagement is clearly crucial, further emphasising the need to explore such schemes in their local context.

\section{The CPD Route to Fellowships of the HEA at Leeds Beckett University as a form of staff development}

The scheme was developed and managed from within a central unit, the Centre for Learning and Teaching (CLT), primarily led by a scheme lead (a senior academic staff member with a cross-University leadership role for academic staff development) and a scheme manager responsible for its operation. A senior member of academic staff from each of the University's faculties was also involved in the development and operation of the scheme, shaping the process and aiming to secure support and participation within their faculty. These faculty leads delivered scheme inductions to new participants in which the process of taking part was introduced and the underpinning UKPSF was outlined. The faculty leads also acted as 'critical friends' to participants from different faculties to their own. As the scheme expanded, a pool of further critical friends was developed made up of those who had achieved fellowships through the scheme and were prepared to act as critical friends to others on a voluntary basis. The key role of the critical friend was to guide participants to selecting an appropriate level of fellowship to aim for, and to support them through the scheme with a suggested 2-3 meetings called by participants to discuss and review the development of their case for fellowship and supporting evidence.

A key resource for the scheme was a handbook provided to participants, critical friends and reviewers detailing the scheme and the UKPSF, providing guidance about 
the process and incorporating evaluation and planning tools to guide engagement. This handbook was also supplemented by a space within the University's Virtual Learning Environment (VLE) providing links to key resources related to each of the UKPSF dimensions along with exemplars and guidance on how to develop and present the case for fellowship at review meetings. Participants were presented with the need to undertake a process involving four stages of activity: engaging, recording, synthesising, and preparing and submitting for review. This process would then lead to the development of 'narratives' linked to the dimensions of the UKPSF and supported by evidence from a 'portfolio' to show sustained engagement, theoretical underpinnings, critical reflection, and responses to student feedback.

The review meetings consisted of a presentation/dialogue with supporting evidence presented on screen to a panel of reviewers made up of faculty leads from different faculties to those of participants. Again, as the scheme developed, further reviewers were brought in from each faculty to conduct reviews. The review meetings were screen recorded so that the case for fellowship and supporting evidence displayed on screen could be captured and these were used to support decision making and moderation of outcomes. There was an initial requirement that the University's eportfolio tool should be used in the development and presentation of the narratives for the review meeting, but this was relaxed and then removed. Following feedback related to the time required to get to grips with the software, the use of more familiar tools was mandated and a PowerPoint presentation with links to files providing supporting evidence became the most common approach to presenting the case at review meetings. The nature of the review meetings also shifted over time. Initially, there was an expectation that the review would take the form of a 'dialogue', with the reviewer and participant engaging in discussion throughout. Later, however, concerns over the 
reliability and equity of the assessment process combined with a need to clarify expectations and ensure systematic coverage of the UKPSF dimensions led to further standardisation of the process which increasingly took the form of a presentation with scope for questions at the end.

The rationale for the scheme presented in the case for accreditation is one primarily of 'staff development' and it clearly set out to formalise engagement with CPD activities. As the handbook states:

This should be a developmental process through which you are also able to evidence how personal reflection, the peer observation of teaching, consideration of student feedback, research, and action continues to inform your own learning and teaching practice (Leeds Beckett University, 2015, p. 6).

This rationale is contextualised within the need to provide support for the achievement of the learning and teaching related aspects of the University's strategic plan. In terms of Land's model, the scheme can thus be clearly identified as 'domesticating' in nature, showing a managerial orientation in developing staff towards institutional goals and missions within a managerial and hierarchical organisational culture (Land, 2001, p. 7). The managerial hierarchical elements of the scheme are clearest in the presentation of an institutional target for HEA fellowships with goals of 70 staff required to achieve Senior Fellowship (D3) by September 2014 and of $80 \%$ of academic staff to gain Fellowships (D2) by September 2015. These targets shaped the organisation and structure of the scheme to ensure that performance could be measured and regular data could be provided to faculty management to monitor and manage the process through a hierarchical operation via Heads of Schools, through senior academic staff with line management responsibilities for different groups of teaching staff. This was carried out through the people development review (PDR) process, an annual appraisal in which targets from the previous year are reviewed and new targets for the forthcoming year 
are discussed. A discussion about HEA fellowships became a mandatory agenda item across the University for PDR discussions. This led to increased participation and, whilst the target was not fully achieved across the University in the timescales, the proportion of staff with fellowships increased substantially over the period.

\section{Acknowledging complexity through the application of practice theories}

Whilst the scheme brought about a rapid increase in the proportion of staff with fellowships over the period, this in itself will not suffice as an indication of its developmental impact given the difficulties of assuming that participation will necessarily result in particular effects. The nature and depth of engagement with the scheme must be considered in order to explore its effects on participants and its potential as a form of development to change practices. Practice theories offer much potential in conceptualising and exploring this engagement, offering an alternative to methodological individualism by acknowledging the complex interplay between structure and agency, between people and things, and between individuals and groups (Hager, Lee, \& Reich, 2012). In terms of the development process, Lee and Dunston (2011, p. 490) state that:

\footnotetext{
a theorisation of learning is required that is associated with a complex, sociomaterial understanding of practice. This theorisation goes beyond attending exclusively to individual knowledge, skill and competence, and requires attending to the relational, organisational and material conditions that shape practices and the emergence of new practices in particular settings.
}

Fundamentally, the scheme is focused on individual fellowship applications, but the importance of the workgroup as the locus of meaningful change within different teaching and learning 'regimes' and the importance of a host of cultural aspects that 'shape' the meanings and trajectory of change initiatives at this level needs to be 
considered (Trowler, 2008a). Following Nicolini's (2008) 'theory-method package' an attempt was made to 'zoom in' on participant engagement in the scheme as a form of practice and to 'zoom out' to consider interrelationships with other practices. The 'zooming in' process aimed to focus on the nature of the practices involved in taking part in the scheme, their location and timing, the tools and resources employed, and the interactional exchanges involved. The 'zooming out' then attempted to explore how the practice of taking part related to other teaching and learning practices. This aimed to uncover whether engagement with the scheme went beyond a form of relatively isolated individual practice by considering the 'meshes' with other practices related to learning and teaching in HE such as course design, teaching and assessment practices.

I undertook in-depth interviews, aiming to reveal what Trowler (2008b, p. 149) describes as a relatively 'detailed picture of a small area' to explore the nature of the practices involved in participation and the extent of their interaction with the broader 'nexus' of practices related to teaching and learning (Saunders et. al., 2015). Having obtained ethical clearance to undertake the study, I invited all staff within the Faculty of Health and Social Sciences who had completed the scheme between late 2014 and early $2016(n=34)$ to take part. Interviews were carried out with all those who accepted $(n=19)$ and representatives from all of the faculty's three schools were included. The demographic spread was generally representative of the faculty but all were full-time academics with a substantial teaching element to their role. This might be expected given the focus of the scheme but a number of PhD students and staff with researchfocused roles had also undertaken fellowships during this period and these groups were not represented. It is not possible to be sure of reasons for their lack of participation, but it may be that they were less positive about the scheme seeing less of a fit with their role. This was the perception amongst the faculty lead and other senior staff who felt 
that this was an issue for research staff in the faculty who had been included in the target but were considered not to have roles that made participation straightforward.

Participants had a range of teaching and learning-related roles and responsibilities from module leaders through to course leaders and those with management responsibilities for other academic staff or oversight of particular aspects of provision across schools or subject areas. Most, but by no means all, had professional backgrounds in fields of Health and Social Care such as Nursing, Physiotherapy, Counselling, Social Work and Youth and Community Work. The majority had experience as practitioners in health, psychological and social work fields and maintained registration with professional and regulatory bodies such as the Health and Care Professions Council (HCPC), the Nursing and Midwifery Council (NMC) and the Charted Society of Physiotherapy (CSP). Although staff from health care professional backgrounds predominated, participants brought a broad range of experiences and approaches to the scheme. The interviews were transcribed and thematic analysis was carried out focusing particularly on patterns of engagement with the scheme, motivations for taking part, and perceptions of impact. This attempted to explore how far it was experienced as a relatively isolated and 'one-off' activity, perhaps more characteristic of 'box ticking' approaches and how far it may have interfaced with other practices to contribute to change.

Doubts have to be acknowledged as to how far practices can be revealed without direct observation. As Nicolini (2008, p. 14) reminds us, there are clear limits on the extent to which accounts of practitioners gleaned through 'off-line, after-the-fact interviews' can reveal genuine insight into their actual practices. However, the interviews certainly provided insights into the scheme as a form of practice. Whilst the focus was placed on how participants experienced the process and what engagement 
involved, the choices they made when characterising their engagement and reporting their attitudes and motivations revealed much about these practices. As Saunders and colleagues (2015, p. 56) make clear, a focus on 'affects, values and beliefs' can be illuminating in gauging the extent to which practice change is being successfully effected.

\section{'Zooming in': Patterns of engagement}

As might be expected given the number of participants interviewed from different areas of the faculty, each individual seemed to experience the process in different ways depending on many factors such as how it was introduced by local management, who they interacted with both from the scheme and more locally, and their role with regard to teaching and learning within their wider team. However, there were clear patterns in how the majority of participants interacted with it.

In most cases initial engagement consisted of attendance in an induction session followed by the organisation of an initial meeting with an allocated critical friend. Most described difficulties in negotiating the requirements of the scheme in the initial stages and a lack of time to engage led many to 'park' the scheme until a more opportune time. Peat (2015, p. 95) observes that a deadline may be important in countering a tendency for the process involved in institutional schemes to 'drift' and the scheme manager took a proactive approach to encouraging participants to book a review meeting at an early stage as well as to make contact with their critical friend. Alongside the annual cycle of target setting and review within the PDR process, this seems to have been a key driver for the timing of engagement. Most engaged in brief periods of intensive activity, studying the requirements of the scheme and considering examples of how their activities could be mapped onto the UKPSF, and then 'pulling together' the review. This was generally done in allocated 'blocks' of time before key points such as critical 
friend meetings or the review meeting itself. Reflecting this pattern of engagement, intensive one-day 'portfolio development' and 'fast track' sessions were organised aiming to provide participants with the time and space to work on narratives and evidence gathering with the support of faculty leads.

Levels of support provided within the scheme tended to be positively regarded in terms of helping participants to 'get through it' successfully. Participants referred to the examples and guidance material provided, and most had had at least one meeting with their critical friend. Generally, but not unanimously, these meetings were felt to be of benefit though this was characterised very much in terms of navigating the requirements of the scheme rather than any broader discussion or sharing of teaching practices. The focus was placed on aspects such as clarifying guidelines, seeing examples, and rehearsing presentations. In most cases, critical friend meetings were also supplemented with informal support and discussion with immediate colleagues who had completed the scheme. Generally, this support also seemed to consist of discussions around examples and scheme requirements rather than broader discussions about teaching practices. For most, the process was characterised as entirely individual though some participants undertook the scheme at the same time as colleagues from the same course team and described this positively as an opportunity to share ideas and offer encouragement.

Some described a process whereby once they had awareness of the UKPSF, they underwent a process of reflecting on their ongoing activities 'in the background'. Others described activities that they felt they may not have otherwise engaged in and that took place outside these periods of intense activity such as revisiting draft papers on pedagogic research that they had previously 'shelved', or taking part in university teaching and learning workshops. Two participants described a process of embarking 
on changes to modules and evaluating teaching and learning activities more thoroughly in response to the requirements of the scheme. These were exceptions however, and the majority described engagement as retrospective and focused specifically on the demands of the scheme and the development of the review narratives. Most clearly felt that they could adequately attend to the scheme requirements through drawing on work that they had already undertaken and did not feel the need to engage in immediate changes to their everyday practices in order to do this.

In general, these patterns of engagement are consistent with van der Sluis and colleagues' (2016) conception of a relatively mechanistic 'retrospective benchmarking' approach to evidencing mastery of the UKPSF dimensions through retrospective reflection rather than ongoing development activity. Given the nature of the reported motivations for taking part, this is perhaps unsurprising. For most, achievement of a fellowship had been negotiated as a PDR target and there was strong awareness of the university target. Most cited this as the primary motivation for taking part though there were other individual factors intertwined within this linked to career development, prospects of advancement and a perception of a need to formalise years of experience in the changing marketplace of HE. This was particularly the case for those in relatively early career stages or those exploring possibilities for advancement or seeking employment in other institutions. Motivations were thus largely strategic and linked to individual job security, awareness of institutional drivers and broader political imperatives rather than focused on professional development and the improvement of teaching and learning. Again, this is consistent with the motivations identified in the studies of Spowart and colleagues (2015) and van de Sluis and colleagues (2016).

Despite the fact that, for many, the presence of the target and management imperatives led them to feel that their participation was largely driven by external 
motivations, many participants embarked on a process which they found valuable and which gave them a sense of 'ownership'. Even participants who described very negative initial reactions to the idea of having to take part reported benefits to their participation. As one participant stated:

I found it quite an enlightening experience so I got quite a lot out of it and that surprised me because I was resistant to that; I wasn't open to it at all. I was doing it because I had to but actually in that journey I found it really surprising how joined up all my activities have been and how that constant focus has been there and how that theoretical basis is coherent with what I deliver.

Mostly these benefits were described in terms of reflective learning, taking stock and having a sense of affirmation of existing teaching and learning practices:

I think it's a really healthy process for teachers to take stock of how they've developed the work they've done and to look at it in the round - we often don't do that I think.

This sense of affirmation seemed to be particularly strong amongst those who had become lecturers relatively late in their careers after a period of professional practice:

It was almost like affirmation of the role - it almost made me feel worthy of being a lecturer because coming in to HE through the back door initially as a clinician but then being around people with $\mathrm{PhD}$ and professorships I always felt like - do I belong here? Am I just winging this? But then looking at it thinking well if this is what's required of me it looks like I'm doing it right so from that perspective I think it was good.

It was clear that engagement in the process allowed many participants to take stock of their professional roles explicitly which they may not have had the opportunity to do for some time: 
I struggled to get going to begin with because you're so involved in the day job that you don't perhaps always think about why you do something the way you do it and you don't always think about your values or your philosophy or why you actually think that's the way to do it because that's been developed over a long period of time and it's sort of become ingrained in your practice.

And it was clear that for many this process was perceived positively:

I think my view of myself as a tutor has changed a little bit - rather than being a professional who teaches I'm thinking I'm a professional educator and higher education lecturer and that I deserve to be here... I ended up finding language; a certain security and satisfaction to be able to find a way to say this is me and this is what I do and to be able to explain it better.

Most were positive about the nature of the scheme as inclusive, flexible, wellmanaged and appropriately achievable. It was not considered to be overly-onerous and there was a perception that it could enable different people with different approaches and priorities to approach it in ways that were most appropriate to them:

I welcome the fact that it wasn't an arduous process and that it recognised that I had all of this experience... If it had been more arduous, I might have questioned it a bit.

For many there was a strong sense of pragmatism about the process and a recognition that it had been responsive to participants' needs in, for example, the removal of the requirements around portfolio development and that it had been set up to keep the time required to a minimum which was valued:

...it's a good thing but I don't know if it will be that influential as time goes on. The good thing is it's done and the University wanted doing and I've done it and it wasn't too hard so that's fine. Everybody's happy really. 
It has to be remembered that only those who successfully took part in the scheme were included in the research, though in a small number of cases participants were referred or offered fellowship at D2 (Fellow) rather than the senior fellowship (D3) that they applied for. In most cases, therefore, there were no assessment-related 'critical incidents'. Given Trowler's (2008a) observation that incompatibilities between the values, attitudes and practices of participants and those 'instantiated' within development activities may frequently only be revealed through such critical incidents, this may result in a representation of engagement in the scheme which is overly positive. Despite the potential for problems emerging from target-driven approaches, however, overall perceptions of taking part in the scheme were certainly not negative and tended to range from a generally neutral sense that it had done 'no harm' to a clearly positive sense of validation and affirmation of professional practices.

\section{'Zooming out': Outcomes and interfaces}

In exploring the 'meshes' between the practices involved in taking part in the scheme and the broader practices involved in teaching and learning, overt connections appear to have been limited. The reflective 'portfolio-building' structure provided potential for the process to be one that could operate within the spatial, temporal, personal and social location of participants (Boud \& Brew, 2013) allowing them to relate ongoing activities to the UKPSF and to capture this process in portfolio form near to the moment and location of practice. However, engagement tended to occur at times and places where individuals could have the 'space' to take part in intensive activities that were almost entirely retrospective. Despite the fact that participants reported many positive aspects at an individual level, it is clear that the scheme was seen as a relatively isolated activity, and for all participants, direct involvement in 'portfolio building' activities ended once a fellowship had been achieved. For most, the retrospective focus 
appears to have largely restricted participation to a 'reframing' of previous activities rather than acting as a direct stimulus to changes in learning and teaching practices.

Whilst this appears to have placed limits on the scheme's developmental impact, it is important to acknowledge the potential limitations of an approach based largely on interviews rather than observation. Considerations of the effects of engagement in the scheme on broader practices are limited to those perceived by participants. This is only a methodological issue in part given the increasing acknowledgement of emergence and the unpredictability of effects as well as the impossibility of understanding practices in full. Some aspects will inevitably remain tacit and 'somewhat elusive' (Hager et al., 2012, p. 5). Subtle and tacit changes to the learning and teaching-related practices of participants may have been effected during the process of getting to grips with the standards and linking them to experiences and this may have been taken forward into similarly subtle and tacit changes in ongoing practices. Clearly, a longer-term perspective would be potentially beneficial. For example, it is only possible at this stage to speculate what the effects may be of the increased sense of affirmation that many derived from taking part. This may have an impact on the extent and depth of ongoing engagement with learning and teaching development, as may any attempts by participants to move on to the next level of fellowship. Exploring these linkages and attempting to follow them through to a consideration of student outcomes and experiences will require further research. There are also plans to intensify the possibilities for involving participants in ongoing networks and the longer-term effects of this are not yet knowable. However, in most cases, any impact on wider teaching and learning practices was too indirect or subtle to be noted by participants. The timing and location of the practices involved in participation appear to have largely insulated the 
scheme from the everyday practices of participants regardless of reported benefits at the level of the individual.

This separation was particularly manifest in a reported sense that the scheme in its current form perhaps represents a missed opportunity in terms of development. When discussing their engagement in the scheme, many participants lamented the fact that little emphasis is placed on elements of planning and future focus. This issue emerged most fully in discussions on the idea of ongoing good standing, and a potential future need to maintain evidence of ongoing continuing professional development, a process very familiar to many participants through existing good-standing requirements from their professional bodies. Participants were positive about this in general terms, but there was a sense of distance from a scenario in which ongoing good-standing processes would be accepted practice. This would necessitate a change in the status and recognition of CPD in order for good standing to be meaningful. Time would need to be allocated, support would need to be provided, integration with CPD programmes and the PDR system would need to be achieved, and it would need to become an everyday part of the landscape of higher education. Many felt that this would require a further shift in perceptions of the value of teaching both within the University and across the sector as a whole. Again, there was a clear perception of distance from an ideal scenario in which teaching and learning would be valued in terms of reward and recognition. These 'current realities' also seem to have impacted on the scheme itself and how it was presented and enacted over time.

\section{Conclusion}

As the scheme approaches review and revalidation, it may be that considering the possibilities for development within rather than outside the everyday context of practice, through a more process-oriented and future-focused approach, may prove to be 
of benefit. Similar conclusions are highlighted by Spowart and colleagues (2015) who see a potentially fruitful focus for the development of their scheme in further embedding and contextualisation at the level of local teaching communities. However, the success of such an approach is likely to require further shifts in the status of learning and teaching within the institution along with more integrated CPD practices. Without this shift, there is clearly a danger that the perceived benefits of the scheme as an appropriately achievable and personally affirming method of gaining accreditation of participants' teaching experience would be undermined, particularly in the absence of clear processes for ongoing good standing across the sector. In common with Spowart and colleagues (2015) and van der Sluis and colleagues' (2016) findings, this study suggests that further work needs to be done both to explore the impact of competencydriven professional accreditation schemes and to maximise their ongoing developmental impact as a form of deep learning in practice rather than as dislocated box ticking. Those looking to learn from the UK experience would perhaps be well advised to wait to see if evidence emerges to suggest that such schemes can do more as a force for development than simply provide a mechanism for one-off retrospective benchmarking. As yet, there are few grounds for suggesting that this is the case, though the increased engagement and retrospective affirmation at the level of the individual may at least be considered a step in the right direction.

\section{List of references}

Boud, D., \& Brew, A. (2013). Reconceptualising academic work as professional practice: implications for academic development. International Journal for Academic Development, 18(3), 208-221. 
Crawford, K. (2010). Influences on academics' approaches to development: voices from below. International Journal for Academic Development, 15(3), 189-202.

Devlin, M., \& Samarawickrema, G. (2010). The criteria of effective teaching in a changing higher education context. Higher Education Research \& Development, 29(2), 111-124.

Hager, P., Lee, A., \& Reich, A. (2012). Problematising practice, reconceptualising learning and imagining change. In P. Hager, A. Lee \& A. Reich (Eds.), Practice, learning and change (pp.1-14). Dordrecht: Springer.

Higher Education Academy. (2015). HEA accredits its 100th institutional CPD scheme. Retrieved from https://www.heacademy.ac.uk/about/news/hea-accredits-its-100thinstitutional-cpd-scheme

Hibbert, P., \& Semler, M. (2015). Faculty development in teaching and learning: the UK framework and current debates. Innovations in Education and Teaching International. http://doi.org/10.1080/14703297.2015.1022201

Land, R. (2001). Agency, context and change in academic development. International journal for academic development, 6(1), 4-20.

Land, R., \& Gordon, G. (2015). Teaching excellence initiatives: modalities and operational factors. York: HEA.

Lee, R., \& Dunston, R. (2011). Practice, learning and change: towards a retheorisation of professional education. Teaching in Higher Education, 16(5), 483-494. Leeds Beckett University. (2015). Fellowships of the Higher Education Academy Handbook.

Nicolini, D. (2008). Practice theory, work and organisation. Oxford: OUP. 
Peat, J. (2015). Getting down to the nitty-gritty: the trials and tribulations of an institutional professional recognition scheme. Perspectives: Policy and practice in Higher Education, 19(3), 92-95.

Saunders, M., Sin, C., \& Dempster, S. (2015). Evaluative research in Higher Education policy analysis. Theory and Method in Higher Education Research, 1, 49-69.

Spowart, L., Turner, R., Shenton, D., \& Kneale, P. (2015). “But I've been teaching for 20 years...": encouraging teaching accreditation for experienced staff working in higher education. International Journal for Academic Development, 21(3), 1-13.

Thornton, T. (2014). Professional recognition: promoting recognition through the Higher Education Academy in a UK higher education institution. Tertiary Education and Management, 20(3), 225-238.

Teelken, C. (2012). Compliance or pragmatism: how do academics deal with managerialism in higher education? A comparative study in three countries. Studies in Higher Education, 37(3), 271-290.

Trowler, P. (2008a). Cultures and change in Higher Education. Basingstoke: Palgrave Macmillan.

Trowler, P. (2008b). Editorial: introduction. International Journal of Educational Research, 47(3), 149-150.

Trowler, P., \& Cooper, A. (2002). Teaching and Learning Regimes: Implicit theories and recurrent practices in the enhancement of teaching and learning through educational development programmes. Higher Education Research \& Development, 21(3), 221-240. Turner, N., Oliver, M., Mckenna, C., Smith, H., Deepwell, F., \& Shrives, L. (2013). Measuring the impact of the UK Professional Standards Framework for Teaching and Supporting Learning (UKPSF). SEDA/HEA: London. 
van de Sluis, H., Burden, P., \& Huet, I. (2016) The evaluation of an institutional UKPSF recognition scheme. Educational developments, 17(1), 5-9. 